\title{
Nuclear Cardiac Stress Testing in the Era of Molecular Medicine*
}

\author{
Mark R. Vesely and Vasken Dilsizian
}

The objective of cardiac stress testing is to detect coronary artery disease (CAD) and to prevent future adverse events, such as myocardial infarction or death. The progression from electrocardiographically based stress testing to current SPECT and PET technologies has brought improvements in diagnostic efficacy and resolution. Myocardial perfusion imaging facilitates management of CAD in elective and acute settings by providing valuable diagnostic and prognostic information. Hybrid PET/CT and SPECT/CT systems impart complementary information of coronary anatomy and its physiologic significance on blood flow reserve. In the current era, diagnosis and treatment of cardiovascular disease is increasingly defined by underlying molecular and genomic aberrations rather than by clinical signs and symptoms alone. Nuclear imaging is uniquely primed to exploit the targeting of expressed cell-surface molecules and intracellular processes of cardiovascular disease and to foster the development of innovative therapeutic interventions in the future.

J Nucl Med 2008; 49:399-413

DOI: 10.2967/jnumed.107.033530

$\mathbf{T}$

he prevalence of coronary artery disease (CAD) and the resultant death rate in the United States is staggering. Cardiovascular disease remains the number one cause of mortality in the United States, with the rate of CAD deaths exceeding that of stroke by a ratio of $2: 1$ to $3: 1(1,2)$. The lifetime risk of developing CAD after $40 \mathrm{y}$ of age is $49 \%$ for men and $32 \%$ for women (3). Thus, early detection of CAD to prevent myocardial infarction or cardiac death is the primary objective of noninvasive cardiac stress testing.

Cardiac stress testing originated and continues to evolve from the need to identify clinically significant CAD. Additionally, the physiologic significance of CAD burden provides prognostic information in settings such as postmyocardial

\footnotetext{
Received Feb. 22, 2007; revision accepted Oct. 12, 2007.

For correspondence or reprints contact: Vasken Dilsizian, MD, Division of Nuclear Medicine, Department of Diagnostic Radiology, University of Maryland Hospital and School of Medicine, 22 S. Greene St., Gudelsky Building, Room N2W78, Baltimore, MD 21201-1595.

E-mail: vdilsizian@umm.edu

*NOTE: FOR CE CREDIT, YOU CAN ACCESS THIS ACTIVITY THROUGH THE SNM WEB SITE (http://www.snm.org/ce_online) THROUGH MARCH 2009.

Dr. Dilsizian reports having an investment interest with GE Healthcare and Molecular Insight Pharma. No other potential conflict of interest relevant to this article was reported. Drs. Dilsizian and Vesely discuss investigational devices/drugs not yet approved by the FDA.

COPYRIGHT @ 2008 by the Society of Nuclear Medicine, Inc.
}

infarction and preoperative states. However, acute coronary syndrome (ACS), with its associated high morbidity and mortality, is a common initial presentation of CAD and has been difficult to predict and prevent. Therefore, detection of $\mathrm{CAD}$ in the subclinical setting or during symptomatic presentation as ACS should be a foremost goal of cardiac stress testing in the future. Stress testing will accordingly allow tailored management in both additional diagnostic and therapeutic procedures as well as adjustment of medical therapies.

\section{PHYSIOLOGY OF FLOW-LIMITING CORONARY ARTERY LESIONS}

Exercise serves as a cardiac stress by increasing myocardial demand through increased heart rate, contractility, and blood pressure. In healthy coronary arteries, increased myocardial oxygen demand is met by increased blood flow. The rate of blood flow through a coronary artery is critically dependent on the driving pressure gradient and the resistance of the vascular bed. When oxygen demand increases, physiologic mechanisms-such as release of endothelial nitric oxide-result in arterial vasodilation and, thus, enhanced blood flow. In normal coronary arteries, resting myocardial blood flow is $\sim 1 \mathrm{~mL} / \mathrm{g} / \mathrm{min}$ but can increase 2- to 3-fold with exercise. Because the pressure drop across a stenosis varies directly with the length of the stenosis and inversely with the fourth power of the radius (Bernoulli's theorem), resistance almost triples as the severity of coronary artery stenosis increases from $80 \%$ to $90 \%$. Whereas $>80 \%$ stenosis is required to cause resting ischemia, atherosclerosis limits compensatory vasodilatation such that impedance of flow can occur once coronary stenosis exceeds $40 \%-50 \%$ (4). Thus, increased myocardial demand from exercise can lead to ischemia in tissue perfused by moderately stenosed coronary arteries. The resulting stepwise series of physiologic perturbations, including regional wall motion abnormalities, ischemic ECG changes, and chest pain, serve as the signals detected by many current stress test techniques. Because decreased perfusion by narrowed coronary arteries precedes the steps of this "ischemic cascade," myocardial perfusion imaging has an inherent advantage over ECG-based or regional wall motion-based techniques for detecting CAD.

\section{Exercise-ECG Stress Test}

Current Stress Test Modalities. The electrocardiogram (ECG) was recognized as a tool for detection of CAD 
as early as 1928 with the observation of exercise-induced ST- and T-wave changes in patients with chronic stable angina (5). The development of a standardized exercise stress protocol for evaluation of functional capacity and "circulatory efficiency" followed in the subsequent year (6). The use of ECG monitoring to detect exercise-induced myocardial ischemia from coronary insufficiency in the clinical setting was reported in 1941 (7). The observation that exercise produces a marker not seen in resting conditions serves as the foundation of the 2-component structure of current stress testing modalities - a stressor and a subsequent detectable signal.

Currently accepted ECG criteria for the detection of occlusive CAD is the development of 1-mm horizontal or downsloping ST segment depression in at least 2 contiguous ECG leads. A meta-analysis of 147 consecutive reports, encompassing 24,074 patients who had both exercise stress testing and coronary angiography, demonstrated a mean sensitivity of $68 \%$ and a specificity of $77 \%$ (8). Yet, many of these studies have limitations, such as patient referral bias, which refers to inclusion of study subjects based on test results. A more focused review of the literature with adjustment for these biases demonstrates a sensitivity of $50 \%$ and a specificity of $90 \%$ (9). A notable strength of exercise-ECG stress testing is found in its specificity. However, the low sensitivity of exercise-ECG along with the low prevalence of clinically silent obstructive CAD are 2 factors that inhibit exercise-ECG stress from broad use as a screening tool for CAD in the way that mammography and colonoscopy are for the detection of occult cancer.

Additionally, ischemic ST segment depressions observed with continuous ECG monitoring during stress testing are typically in the inferior and precordial leads and do not necessarily correlate with specific myocardial regions or vascular territories (10). Patients with hemodynamically significant CAD typically have more than a single atherosclerotic lesion and frequently in a multivessel distribution. Although coronary angiography identifies intracoronary luminal narrowing, it has limited ability to assess the physiologic significance of a particular lesion, especially if the luminal narrowing is between $40 \%$ and $70 \%$. The limited sensitivity and negligible regional resolution of myocardial ischemia with ECG monitoring are the 2 driving forces behind the development of additional imaging techniques, such as echocardiography, MRI, and nuclear cardiac imaging. Assessment of regional myocardial perfusion or function as an adjunct to ECG testing can enhance and resolve the regional signal of myocardial ischemia and guide localized therapy of stenosed coronary arteries by percutaneous coronary intervention.

Recent Modifications of ECG Interpretation: Duke Treadmill Score. Although ECG-based detection of significant CAD has a low sensitivity, additional clinically useful information is obtained from the exercise stress test. For example, if chest pain is reproduced on a treadmill, then it is likely to be of cardiac origin, representing angina. On the other hand, if the chest pain is not reproduced on the treadmill, despite achieving an adequate heart rate, then it may guide the clinician to seek noncardiac causes of chest pain, such as gastrointestinal origin that may mimic angina. Additionally, the duration and intensity of tolerated exercise are a measure of functional capacity. These findings can be useful in monitoring the effectiveness of therapy as well as providing prognostic information.

The "Duke Treadmill Score" (DTS) was established after assessment of 2,758 patients who underwent exerciseECG stress testing and coronary angiography (11). This score, which accounts for exercise duration, angina, and degree of ST segment deviation, predicts significant CAD and prognosticates annual mortality risk independently from clinical data, coronary anatomy, and left ventricular (LV) ejection fraction (12). The score is calculated by subtracting both the magnitude in millimeters of exerciseinduced ST deviation $\left(\mathrm{ST}_{\mathrm{dev}}\right)$ and the degree of exerciseinduced angina $\left(\mathrm{ANG}_{\mathrm{ex}}\right.$ : $0=$ none, $1=$ nonlimiting, $2=$ limiting) from the minutes of exercise duration on a standard Bruce protocol $\left(\mathrm{EX}_{\min }\right)$. The range of the DTS is typically -25 to +15 and is derived by the following equation: $\mathrm{DTS}=\mathrm{EX}_{\min }-\left(5 \times \mathrm{ST}_{\mathrm{dev}}\right)-\left(4 \times \mathrm{ANG}_{\mathrm{ex}}\right)$. Lower scores are associated with worse mortality and increased likelihood of significant CAD. Although associated mortality rates have not been assessed with current medical therapies, scores demarcated into 3 risk categories (high-risk, $\leq-11$; moderate risk, +4 to -10 ; low risk, $\geq+5$ ) have been validated $(11,13)$.

In addition, exercise-ECG stress testing has an established role in assessment of patients with known CAD. In such patients, exercise-induced ST segment depression portends an increased risk of future cardiac events, regardless of the presence or absence of exercise-induced angina (12). Moreover, low-level exercise protocols play an important role after admission for an acute myocardial infarction, including assessment of therapeutic adequacy, determination of functional capacity to aid prescription of activity level on discharge, as well as assessment of prognosis (12). Thus, the low cost, wide availability, and multiple scenarios in which prognostic information is obtainable continue to keep exerciseECG stress a widely used testing modality.

\section{Radionuclide Cardiac Imaging}

The introduction of ${ }^{201} \mathrm{Tl}$ myocardial perfusion imaging as an adjunct to ECG treadmill studies in the mid-1970s has evolved into the discipline of nuclear cardiology today $(14,15)$. Advances in both technology and radiopharmaceuticals over the past $30 \mathrm{y}$ have contributed significantly to the maturation of the field. Techniques such as SPECT and PET currently allow assessment for occlusive coronary atherosclerosis by evaluation of myocardial perfusion as well as effects of myocardial hypoperfusion on metabolic activity and contractile function. The initial impetus for noninvasive cardiac stress testing was to determine if a clinical presentation of chest pain is attributed to CAD. Yet, 
the advent of localized therapies to specific vessels with bypass surgery or specific lesions with percutaneous coronary intervention has extended this indication from diagnosing CAD to pinpointing areas of myocardial ischemia and guiding interventional therapies to culprit vascular lesions. Thus, advances in current techniques and initiation of new techniques can be measured by both changes in diagnostic efficacy (sensitivity and specificity for detecting CAD) and resolution efficacy (identifying the culprit lesion for chest pain and myocardial ischemia). The progression from ECG-based stress testing to current SPECT and PET technologies has led to improvements in both diagnostic efficacy and resolution (16-18) (Fig. 1). Notably, the current generation of stress testing modalities has retained the traditional 2-component structure, including both a mode of stress and a mode of signal detection.

Pharmacologic Testing. Many patients referred for stress testing have functional limitations from pulmonary, orthope- dic, peripheral vascular, or neurologic conditions that prevent sufficient physical exercise. An additional advantage of myocardial perfusion-based stress testing over ECG-only testing is the applicability of stress testing to patients with underlying ECG abnormalities that mask dynamic ischemic ECG changes. Ischemic ECG signals may be uninterpretable among patients with abnormal baseline ST segment depression of $>1 \mathrm{~mm}$, electronic pacing, left bundle-branch block, or preexcitation pattern. These shortfalls as well as the limited sensitivity and specificity of ECG-based monitoring have led to the development of alternate methods of stressors with pharmacologic agents that either simulate exercise, such as an adrenergic agent (dobutamine), or induce vasodilation (adenosine or dipyridamole). Although there are several selective adenosine $\mathrm{A}_{2 \mathrm{a}}$ receptor agonists undergoing phase III clinical trials, much of the preliminary results remains unpublished to ensure adequate patent documentation before public disclosure. Importantly, pharmacologic stress is less physiologic

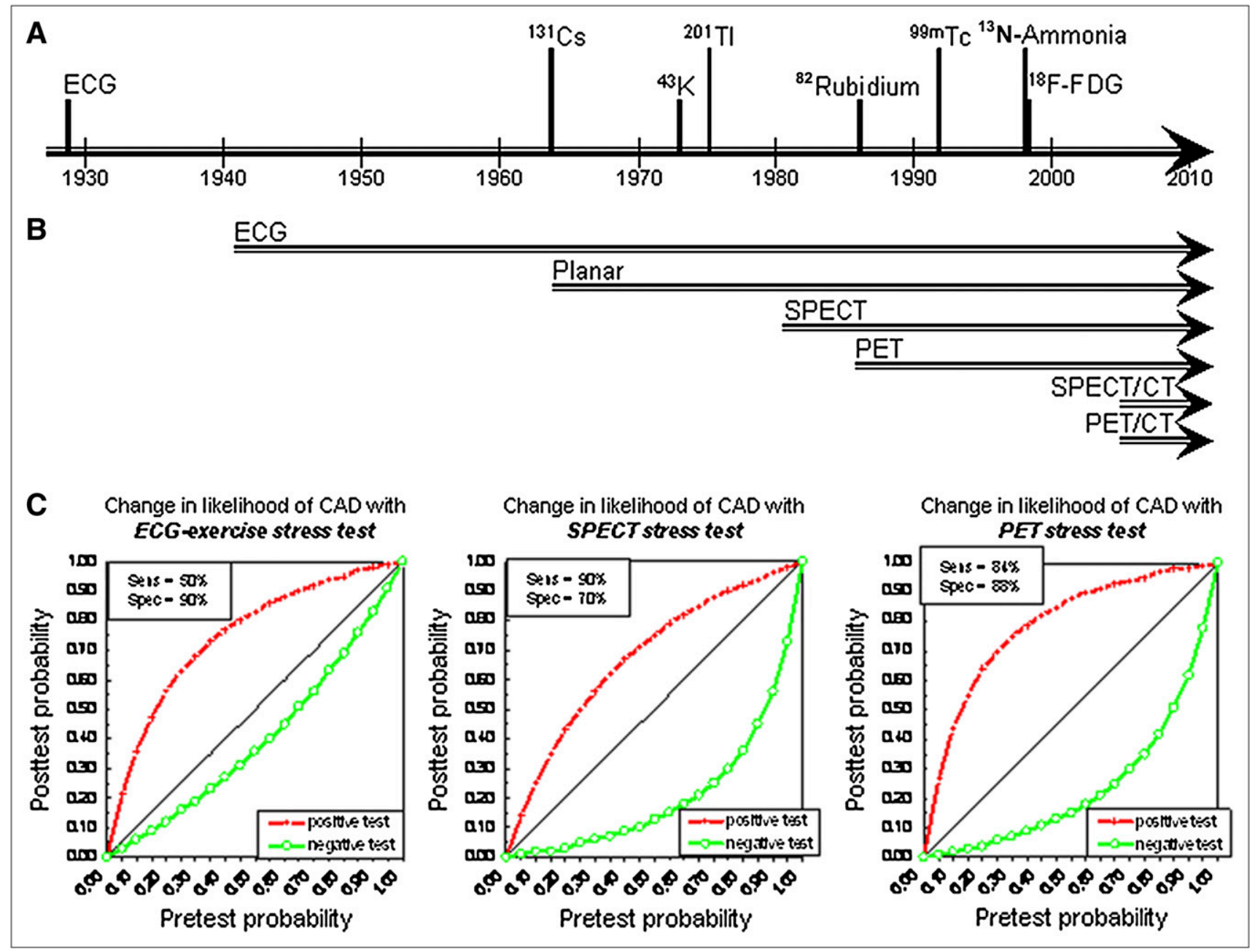

FIGURE 1. Timeline of signal and detector advances in the history of nuclear cardiac stress testing and accuracy of current techniques. (A) Time points of initial recognition that ECG and radiotracers provide diagnostic information for myocardial perfusion and metabolism. (B) Time span of use of detection modalities in cardiac stress testing. (C) Diagnostic information provided by stress testing as change from pretest to posttest likelihood of angiographically confirmed CAD. Bayesian curves are derived from current levels of sensitivity (Sens) and specificity (Spec) for each protocol: ECG-Exercise (16), SPECT (17), and PET (18). 
than exercise, and symptoms during testing (or lack thereof) cannot necessarily be linked to the perfusion pattern.

Radiopharmaceuticals. Progress in development of novel radiopharmaceuticals and myocardial perfusion tracers has paralleled those of instrumentation. The first application of a radiotracer for imaging cardiac tissue dates back to 1964 , when ${ }^{131} \mathrm{Cs}$ was used to detect myocardial infarction (19). Myocardial perfusion imaging with ${ }^{43} \mathrm{~K}$ was introduced in 1973 (14), and its analog, ${ }^{201} \mathrm{Tl}$, was introduced in 1975 (15). By demonstrating greater myocardial extraction and improved defect resolution, thallium became the radiotracer of choice in the clinical setting, as an adjunct to ECG testing. In 1982, cyclotron-produced ${ }^{13} \mathrm{~N}$-ammonia PET myocardial perfusion tracer was shown to have a high sensitivity and specificity for detecting CAD when used with a pharmacologic vasodilator (20). This was followed by the introduction of another PET myocardial perfusion tracer in $1986,{ }^{82} \mathrm{Rb}$, which is generator produced with biologic properties similar to those of potassium and thallium (21). ${ }^{99 \mathrm{~m}}$ Tc-Labeled SPECT myocardial perfusion tracers were introduced in the 1990s, which improve on 2 limitations of thallium-its low-energy spectrum and its long physical half-life. Although three ${ }^{99 m}$ Tc-labeled tracers (sestamibi, teboroxime, and tetrofosmin) have received U.S. Food and Drug Administration (FDA) approval for detection of CAD, only sestamibi and tetrofosmin are available for clinical use at the present time. The characteristics of both SPECT and PET radiotracers with current FDA approval for the detection of CAD are further described in Table 1.

Mechanism of Myocardial Uptake of Radiotracers. Myocardial uptake of a radiotracer is a function of both delivery of the radiotracer to the cell surface (which is flowdependent) and subsequent extraction and retention of the radiotracer into the cell (which is dependent on cell membrane integrity and viability). Intravascular radiotracer is rapidly extracted by myocardial tissue in proportion to blood flow. Thus, the same mechanisms leading to insuf- ficient oxygen delivery and subsequent ECG-detected myocardial ischemia on the treadmill can be assessed directly by interrogating regional myocardial perfusion. Because decreased perfusion by narrowed coronary arteries precedes the steps of the ischemic cascade, myocardial perfusion imaging has an inherent advantage over ECG-based or regional wall motion-based techniques for detecting CAD.

The distribution of radiotracers in various regions of the LV reflects the physiologic consequence of the presence and the extent of epicardial luminal narrowing of coronary arteries and downstream adaptation by the resistance vessels and collaterals. Because such adaptive mechanisms protect the myocardium from ischemia (by decreasing the pressure gradient across a stenotic lesion), exercise or pharmacologic stress is required to exceed these compensatory mechanisms. Regions of decreased myocardial uptake on SPECT and PET can then be correlated with specific coronary artery vascular territories with follow-up angiography and typically with a culprit atherosclerotic lesion responsible for the patient's symptoms. A repeated radiotracer injection and imaging at rest allow for differentiation between reversible and fixed perfusion defects. Reversible defects correlate with myocardial ischemia as seen by dynamic ECG changes between resting and stress conditions. Likewise, defects observed in resting conditions can be reassessed with repeated delayed imaging (usually 3-4 h or $24 \mathrm{~h}$ later) for changes in signal intensity due to radiotracer redistribution (as described with thallium) $(22,23)$. If the defect size decreases from rest to redistribution thallium SPECT (also termed "fill-in" or reversible defect), this signifies hypoperfused but viable myocardium (hibernation), which portends a high likelihood for recovery of function after revascularization (24). On the other hand, a persistent defect from rest to redistribution thallium SPECT (also termed fixed or irreversible defect) signifies scarred myocardium, which portends a low likelihood for recovery of function after revascularization. Whereas ECGstress testing identifies ischemia in a nonlocalized fashion,

TABLE 1

Characteristics of SPECT and PET Radiopharmaceuticals

\begin{tabular}{|c|c|c|c|c|c|c|}
\hline Modality & Tracer & $\begin{array}{l}\text { Usual dose } \\
\qquad(\mathrm{MBq})\end{array}$ & $\begin{array}{l}\text { Photon energy } \\
\text { (keV) }\end{array}$ & $\begin{array}{l}\text { Time to imaging } \\
\text { from injection }\end{array}$ & $\begin{array}{l}\text { Physical } \\
\text { half-life }\end{array}$ & Comments \\
\hline SPECT & $201 \mathrm{TI}$ & $111-166.5$ & 80 & $1-15 \min$ & $73 \mathrm{~h}$ & $\begin{array}{l}\text { Potassium analog } \\
\text { Redistribution with time }\end{array}$ \\
\hline \multirow{3}{*}{ PET } & $\begin{array}{l}\text { 99mTc-Sestamibi } \\
\text { 99mTc-Tetrofosmin }\end{array}$ & $296-1,480$ & 140 & $15-45 \mathrm{~min}$ & $6 \mathrm{~h}$ & $\begin{array}{l}\text { Mitochondrial uptake } \\
\text { Cationic and lipophilic } \\
\text { No significant redistribution }\end{array}$ \\
\hline & ${ }^{82} \mathrm{Rb}$ & $1,110-2,220$ & 511 & $80 \mathrm{~s}$ & $75 \mathrm{~s}$ & $\begin{array}{l}\text { Potassium analog } \\
\text { Generator produced }\end{array}$ \\
\hline & ${ }^{13} \mathrm{~N}-A m m o n i a$ & $370-740$ & 511 & $6 \min$ & $10 \mathrm{~min}$ & $\begin{array}{l}\text { ATP-dependent trapping in cytoplasm } \\
\text { Requires on-site cyclotron }\end{array}$ \\
\hline
\end{tabular}


myocardial perfusion and viability imaging provides additional localized physiologic information that further facilitates local therapies, such as revascularization or coronary interventions (25-27).

\section{Nuclear Cameras}

Both SPECT and PET cameras capture the photons emitted by a radiotracer and convert the information into digital data representing the magnitude of tracer uptake and the location of the emission in the heart. By acquiring dynamic (ECG-gated) scintigraphic data, information on regional and global LV function can be assessed in cinematographic fashion. Thus, the addition of myocardial perfusion imaging to ECG monitoring during stress tests provides substantially greater information than ECG-only stress tests: resolution of regional ischemia, assessment for regional wall motion abnormalities, and myocardial viability.

The 511-keV photons emitted by positron-emitting radiotracers in PET are attenuated less per centimeter of soft tissue than are the lower-energy $80-$ to $140-\mathrm{keV}$ photons typically emitted by SPECT radiotracers. Moreover, the attenuation and scatter algorithm has been well worked out with PET, such that the emission data may be reconstructed into an attenuation-corrected emission image for clinical interpretation. Although similar approaches to PET have been attempted to correct attenuation artifacts in SPECT, these have not been widely adopted because the problem of attenuation correction is fundamentally more challenging in SPECT than in PET. Thus, clear competitive advantages of PET over SPECT include higher spatial and temporal resolution, reliable attenuation and scatter correction, and validated tracer kinetic models for measurement of myocardial perfusion and metabolism in absolute quantitative terms.
Hybrid Cameras: PET/CT and SPECT/CT. With the advent of hybrid PET/CT or SPECT/CT systems, complementary information of coronary anatomy and its physiologic significance on myocardial blood flow reserve can be realized immediately, at the same imaging session (28). Cardiac CT angiography, with resolution of $0.7-$ to $1-\mathrm{mm}$ range, is suited to provide information on the presence and extent of occlusive CAD, although the ability to accurately determine the severity of luminal narrowing in smaller coronary branches is limited, particularly in the presence of extensive calcified disease (29) (Fig. 2). PET and SPECT, on the other hand, are more suited to determine the downstream functional consequences of isolated or sequential anatomic lesions and the status of myocardial viability. The combination of these anatomic and functional modalities is particularly relevant in patients who have an intermediate finding on either myocardial perfusion or CT angiography. Another advantage of the combined scanner is that the corresponding images are spatially aligned, allowing the potential to use the CT image to compute the attenuation map for the myocardial perfusion data (30). One potential problem of using fast CT scans for attenuation correction, however, is the motion of the organs during respiration. The CT scanner "freezes" the heart, lungs, and liver at one point in the respiratory cycle, whereas the PET emission data are averaged over many respiratory cycles. Methods using respiratory gating to correct this problem are currently under investigation. Contraindications to CT coronary angiography include patients with impaired renal function, thyroid dysfunction, or an allergy to iodinecontaining contrast media.

High-Speed SPECT. Several newly designed dedicated cardiac SPECT systems were recently introduced with the goals of achieving higher spatial resolution and sensitivity,

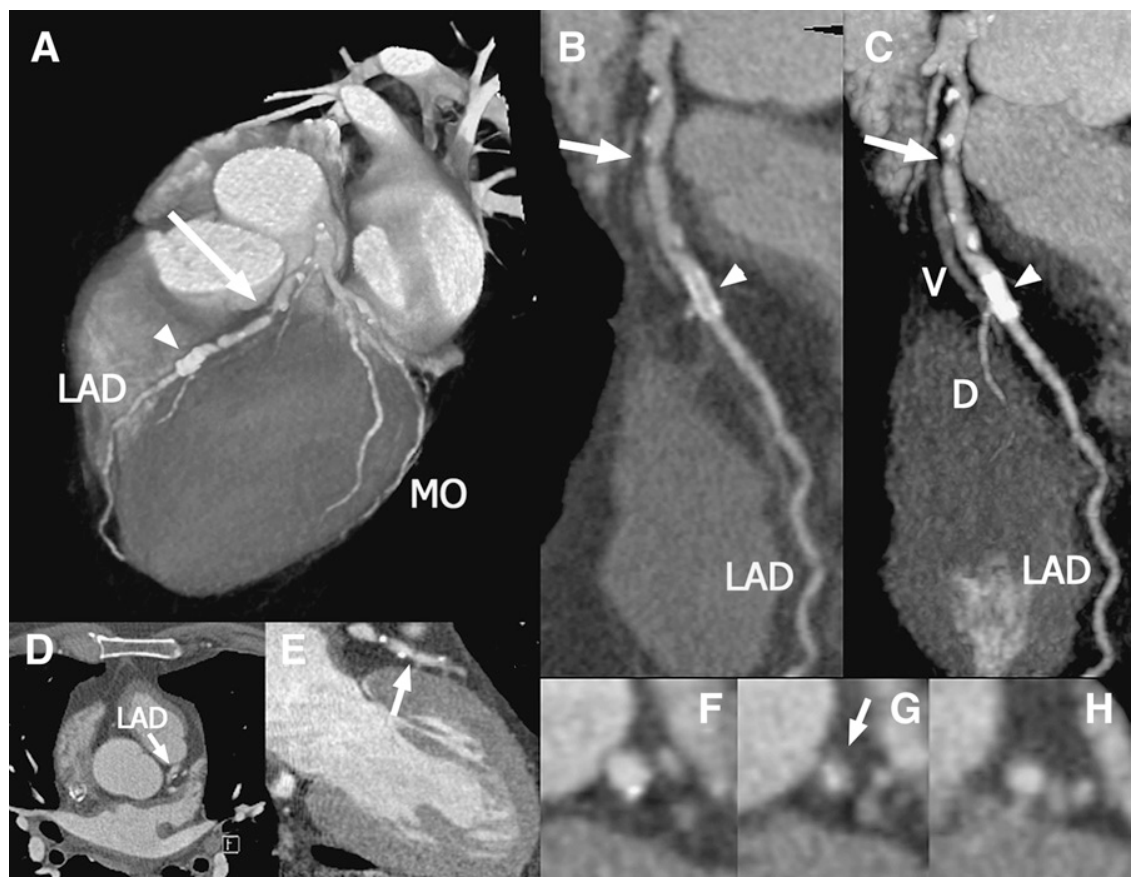

FIGURE 2. CT angiography in a patient who underwent percutaneous coronary intervention of the left anterior descending (LAD) coronary artery in the past and now complains of recurrent angina. Multiple lesions, partially calcified, can be seen in the proximal LAD (D and $E$ ) as well as the stent in mid-LAD. A complete 3-dimensional reconstruction of the heart (A) shows a significant lesion in the LAD (arrow) and the high-density stent (arrowhead). Only a small section of the LAD can be visualized on a single axial slice (B), whereas multiplanar reformations can be created along the vessel and show extended sections (C). Curved multiplanar reformations (D) and maximum-intensity projections (E) can be used to show the entire vessel in a single image. Panels F, G, and $\mathrm{H}$ show crosssections of the LAD at the proximal reference, the stenosis, and the distal reference level, respectively. $\mathrm{MO}=$ marginal branch; $\mathrm{DO}=$ diagonal branch; $\mathrm{V}=$ cardiac vein. (Adapted from (29).) 
while significantly shortening the scan time and improving the patient comfort. By limiting the field of view of the camera to encompass the predictable location of the heart, and changing the crystals, detector, and collimator design, these new SPECT systems are smaller in size and allow simultaneous data acquisition of the heart from all angles (31). Beyond the changes in hardware, advances in software development for image reconstruction, computeraided analysis, and image interpretation will likely increase the competitiveness of nuclear cardiac imaging to that of ultrasound or cardiac magnetic resonance.

\section{Accuracy for Detection of CAD and Prognosis}

Applying state-of-the-art technology and radiopharmaceuticals, the sensitivity and specificity for detecting oc- clusive CAD with gated SPECT is now in the range of $91 \%$ and $72 \%$, respectively (17). PET imparts a higher specificity than SPECT, around $90 \%$, which is most likely a consequence of its superior attenuation correction, increased count-density images, and superior spatial resolution (Fig. 3). Myocardial perfusion imaging now facilitates CAD management in both the elective and the acute settings by providing valuable information on diagnosis as well as prognosis $(17,32)$. Stress myocardial perfusion imaging provides strong prognostic information with identification of low-risk patients. As patients typically referred for stress have an intermediate probability of having CAD, patients with unequivocally normal stress myocardial perfusion SPECT studies have a $<1 \%$ rate of having a future cardiac event (death or acute myocardial infarction) (32).

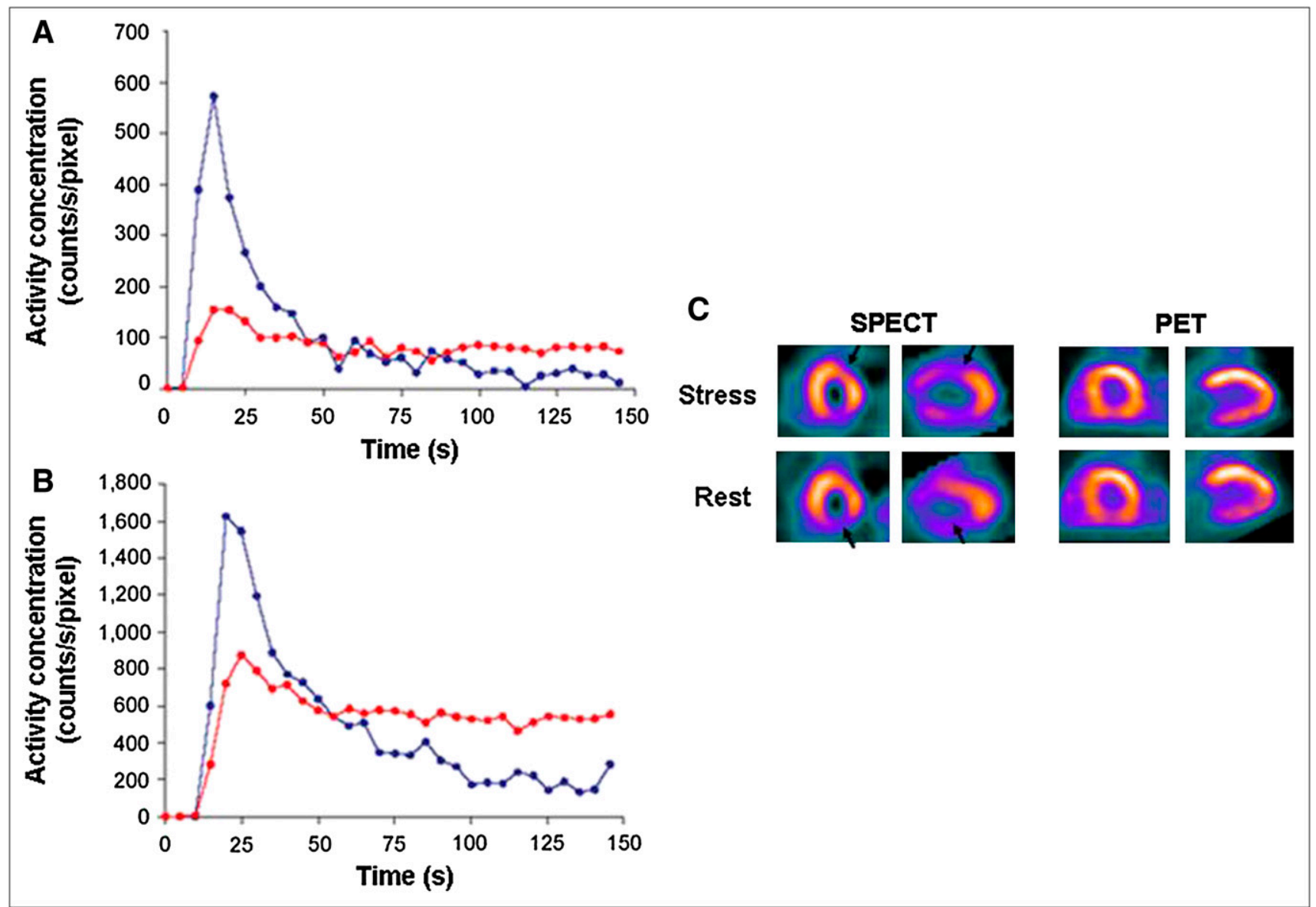

FIGURE 3. ${ }^{82} \mathrm{Rb}$ time-activity curves at rest $(\mathrm{A})$ and after adenosine stress $(\mathrm{B})$. Solid circles represent the activity concentration in left atrium and open circles represent the activity concentration in myocardial tissue. Although the first few minutes after infusion of ${ }^{82} \mathrm{Rb}$ are not usually included in clinical acquisition protocols, it is precisely this period that is of interest if myocardial perfusion is to be quantified. Dynamic imaging of the heart during this time allows analysis of the ${ }^{82} \mathrm{Rb}$ concentration in both arterial blood and myocardial tissue as a function of time. Disparity between myocardial perfusion SPECT and ${ }^{82}$ Rb PET studies is shown (C). Clinically indicated adenosine dual-isotope gated SPECT images (left panel) without attenuation correction show regional 99mTcsestamibi perfusion defect in anterior and inferior regions (arrow). On the rest ${ }^{201} \mathrm{TI}$ images, the anterior defect became reversible while the inferior defect persisted. Corresponding ${ }^{82} \mathrm{Rb}$ PET myocardial perfusion tomograms performed in the same patient are shown on the right panel. PET images were acquired after an infusion of adenosine and $1,110 \mathrm{MBq}$ of ${ }^{82} \mathrm{Rb}$ (top) and at rest after another $1,110-\mathrm{MBq}$ infusion of ${ }^{82} \mathrm{Rb}$ (bottom). ${ }^{82} \mathrm{Rb}$ PET images show normal distribution of radiotracer in all myocardial regions, without evidence for reversible or fixed defects to suggest myocardial ischemia or infarction. Although high-energy positrons of ${ }^{82} \mathrm{Rb}$ degrade spatial resolution and the short half-life increases statistical noise, high-quality images free from attenuation artifacts can be produced with ${ }^{82} \mathrm{Rb}$ PET with only 1,110-MBq injected dose. (Adapted from (28).) 
Similar to SPECT, patients with a normal rubidium PET myocardial perfusion study exhibited only $0.4 \%$ annual cardiac event rates (33). As detector and radiopharmaceutical technologies continue to improve, further enhancement of both diagnostic efficacy and resolution efficacy are expected.

\section{RADIONUCLIDE CARDIAC IMAGING AS ADJUNCT TO ACS MANAGEMENT}

Despite significant aid garnered from myocardial perfusion studies in managing patients with $\mathrm{CAD},>1,300$ deaths secondary to ACS occur daily in the United States (1). Unlike chronic coronary disease, in which impaired coronary blood flow results from slow progression of atherosclerosis in response to chronic endothelial injury, impairment of coronary blood flow in ACS is caused by abrupt plaque rupture, thrombus formation, and vascular occlusion. The incidence of ACS exceeds 1 million patients annually, with an additional 550,000 new cases of angina pectoris each year. In 2000, among those who were diagnosed with ACS, more than a half million patients died secondary to this disorder; representing nearly 1 in 5 adult deaths ( $(1)$.

Although the ECG and biomarkers are the core of initial risk stratification, negative results remain in a substantial number of patients evaluated with acute chest pain symptoms. Of the approximately 8 million patients who present to an emergency department annually with chest pain, nearly 5 million (60\%) are admitted for suspected ischemic etiology and the remaining $40 \%$ are discharged home (3437). Among those who are sent home, 40,000 patients $(1.3 \%)$ subsequently develop an acute myocardial infarction. Of the near 5 million patients who are admitted to the hospital, only $40 \%$ are ultimately diagnosed to have ACS. Thus, evaluation of patients presenting to the emergency room with chest pain is inadequate and consigns a heavy economic burden on the healthcare system.

\section{Myocardial Perfusion Imaging in ACS}

Myocardial perfusion using SPECT has been evaluated in several publications as an effective tool within a chest pain work-up algorithm. Among patients presenting to the emergency department with chest pain, nondiagnostic ECG, and normal initial serum markers and enzymes, myocardial perfusion SPECT has been shown to have a high negative predictive value to rule out myocardial infarction (99\%) or future adverse cardiac events (97\%) (38). Moreover, rest ${ }^{99 \mathrm{~m} T c-s e s t a m i b i}$ SPECT has been shown to improve medical decision making by decreasing unnecessary hospitalizations or prolonged observation periods in the emergency department (39). Thus, to improve diagnosis and risk stratification in patients with chest pain and possible ACS, the use of myocardial perfusion imaging has been assigned a class I, level A, indication by the American College of Cardiology /American Heart Association/ American Society of Nuclear Cardiology (ACC/AHA/ASNC) Radionuclide Imaging Guidelines for the assessment of myo- cardial risk in possible ACS patients with a nondiagnostic ECG and initial normal serum markers and enzymes (38). Similarly, patients with an ST elevation myocardial infarction gain significant prognostic information by noninvasive assessment for LV ejection fraction and the extent of myocardial infarct size and ischemia.

\section{Multislice CT (MSCT) in ACS}

The use of multidetector CT to evaluate patients with acute chest pain has also been shown to be effective in ruling out ACS and facilitating appropriate disposition of patients $(40,41)$. In a recent randomized study (42), of the 461 low-risk patients (negative ECG and biomarkers) presenting to the emergency department with acute chest pain who were screened for the 64-slice CT coronary angiography (MSCT) study, $46 \%$ of patients were excluded due to a history of pulmonary disease sufficient to preclude $\beta$-blocker usage (18\%); allergy to contrast, iodine, or shellfish (12\%); history of CAD (10\%); atrial fibrillation (4\%); and other exclusions (2\%). Given that nearly half of low-risk patients in the emergency department did not qualify to undergo MSCT, the widespread utility of MSCT in the clinical setting becomes questionable. Of the remaining 203 patients who were eligible to enroll, 197 were randomized for evaluation by either MSCT $(n=99)$ or standard of care $(n=98)$ with stress SPECT perfusion imaging (42). Of the 99 patients randomized to the MSCT arm, 24 (24\%) had intermediate or nondiagnostic MSCT results requiring additional testing with SPECT perfusion imaging. In contrast, of the 98 patients who were randomized to the standard-ofcare group (i.e., stress testing with SPECT perfusion imaging), $97 \%$ were directly discharged from the emergency department. There was no difference in office or emergency department visits for recurrent chest pain between the 2 groups $(8.1 \%$ for both), and none suffered major adverse cardiac event over a 6-mo follow-up period. Further studies to assess the efficacy of hybrid PET/CT and SPECT/CT studies in this clinical scenario will be needed as these technologies continue to improve.

\section{Targeting Ischemic Memory}

A possible future approach for risk stratification of patients with suspected ACS involves imaging myocardial fatty acid metabolism. Fatty acid imaging with radioiodine-labeled fatty acid analogs such as ${ }^{123} I-\beta$-methyliodopentadecanoic acid ( ${ }^{123}$ I-BMIPP) using SPECT is an investigational area for the assessment of ischemic memory. After an ischemic episode, abnormalities in fatty acid metabolism may persist long after perfusion has returned to normal, a finding termed "ischemic memory." During this time period, the myocardium garners the bulk of its energy from glucose metabolism.

Among patients presenting to the emergency department with ACS and no prior myocardial infarction, the clinical utility of ${ }^{123}$ I-BMIPP for identifying myocardial ischemia was examined in 111 consecutive patients (43). All patients were admitted and underwent a rest myocardial perfusion SPECT study within $24 \mathrm{~h}$ of chest pain, rest ${ }^{123}$ I-BMIPP 
metabolic images within $48 \mathrm{~h}$ after the perfusion SPECT, and coronary angiography within $1-4 \mathrm{~d}$ of admission. ${ }^{123} \mathrm{I}-$ BMIPP defects at rest were present in $74 \%$ of patients with documented coronary artery stenosis or vasospasm (on ergonovine provocation), whereas only $38 \%$ of patients showed myocardial perfusion defects at rest $(P<0.001)$. Both ${ }^{123}$ I-BMIPP and perfusion studies were normal in nearly $90 \%$ of patients without coronary artery stenosis or vasospasm. These early observations among patients with ACS were subsequently extended to patients experiencing myocardial ischemia during treadmill exercise (44) (Fig. 4). Although ${ }^{123}$ I-BMIPP is approved for clinical use in Japan, it has not yet received approval by the U.S. FDA.

An alternative metabolic approach for assessing myocardial ischemia is with dual-isotope simultaneous acquisition of myocardial perfusion and ${ }^{18}$ F-FDG metabolism (Fig. 5). Among patients who underwent dual intravenous injection of sestamibi and ${ }^{18} \mathrm{~F}-\mathrm{FDG}$ at peak treadmill exercise and simultaneous acquisition 40-60 min after the exercise study, the metabolic signal of ${ }^{18} \mathrm{~F}-\mathrm{FDG}$ was highly sensitive for detecting exercise-induced myocardial ischemia (45). These clinical studies with ${ }^{18}$ F-FDG PET and ${ }^{123}$ I-BMIPP SPECT support the concept that metabolic adaptation likely represents one of the earliest responses to myocardial ischemia. The potential utility of prolonged and persistent metabolic alterations in the heart after an ischemic episode may be best realized among patients presenting to the emergency room with ACS.

\section{THE FUTURE OF NUCLEAR CARDIAC IMAGING: ASSESSMENT FOR SUBCLINICAL CAD}

By design, current myocardial perfusion studies with SPECT and PET detect atherosclerotic lesions that are

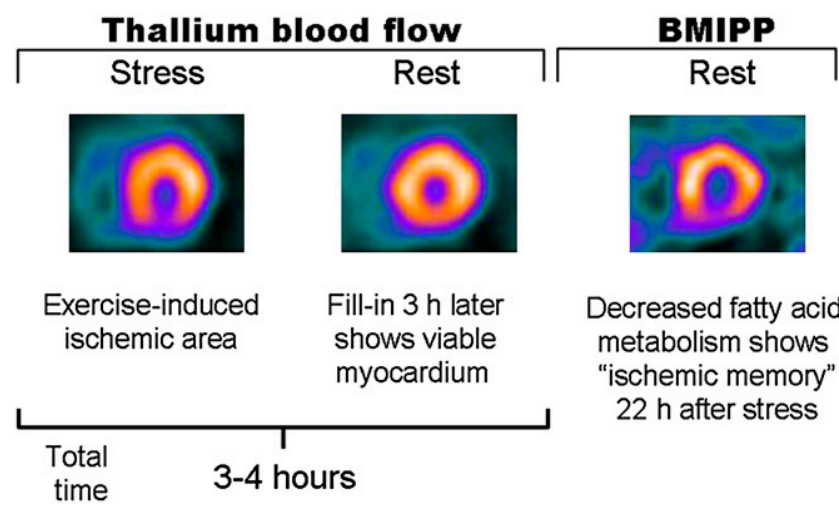

FIGURE 4. Single-photon-emission tomograms demonstrating delayed recovery of regional fatty acid metabolism after transient exercise-induced ischemia, termed ischemic memory. Representative stress (left) and rest reinjection (middle) shortaxis thallium tomograms demonstrate a reversible inferior defect consistent with ischemic but viable myocardium. ${ }^{123}$ BMIPP tomogram (right) injected and acquired at rest $22 \mathrm{~h}$ after exercise-induced ischemia shows persistent metabolic abnormality in inferior region despite complete recovery of regional perfusion at rest, as evidenced by thallium reinjection image. (Adapted from (44).) significant enough to limit myocardial blood flow (typically $>50 \%$ stenosis). Although flow-limiting coronary artery lesions cause angina pectoris, they are not typically prone to rupture (the most common mechanism of acute myocardial infarction). On the other hand, the less mature coronary artery lesions, which are vulnerable to rupture, frequently are not sufficiently narrowed to limit myocardial blood flow. Thus, the current myocardial perfusion imaging toolset has limited sensitivity for screening patients who are at risk for ACS. Therefore, identification of subclinical coronary artery atherosclerosis to enhance primary prevention of CAD, acute myocardial infarction, and sudden cardiac death requires a paradigm shift in the design of next-generation imaging techniques. New methods to detect endothelial dysfunction and early, preclinical atherosclerotic plaques vulnerable to rupture are likely to play critical roles in the realization of this new goal for cardiac stress testing. Rather than assessing for perfusion by cardiomyocyte uptake, radiotracers complexed with molecular markers will be used to specifically target and bind components of interest within atherosclerotic lesions. The metabolic assessment of such PET techniques coupled with anatomic assessment by CT should allow identification and, potentially, prediction of vulnerable plaques in the future.

\section{Screening Asymptomatic Patients}

The application of myocardial perfusion imaging for primary screening of CAD before the occurrence of a significant cardiac event remains limited in the general population. Of the 300,000-450,000 annual events of sudden cardiac death in the United States, nearly $40 \%$ of them can be attributed to previously unrecognized CAD. As asymptomatic occlusive CAD has a prevalence of approximately $20 \%$, such screening would result in a nearly $50 \%$ rate of false-positive tests (Fig. 1). Given the rare but significant inherent risks of stress testing and confirmatory angiography, the utility of stress test-based screening in asymptomatic patients remains unclear. Likewise, percutaneous interventions have not been shown to provide a mortality benefit outside of the ACS setting. As risk factor modifications with lifestyle adjustments and medications remain applicable to the general population, myocardial perfusion imaging is not yet useful for CAD screening in the asymptomatic population, with the exception of those with diabetes mellitus and end-stage renal disease (ESRD).

Diabetes Mellitus. Patients with diabetes are at significant risk for CAD development and cardiac events. An emerging body of literature suggests that approximately $20 \%-40 \%$ of asymptomatic diabetic patients have abnormal myocardial perfusion studies and that such patients may be at even higher risk for events over time (46-48). Although ACC/AHA guidelines at present do not suggest routine screening of asymptomatic diabetic patients, there are ongoing studies of prognosis and randomized trials in asymptomatic diabetic patients, which should clarify the role of myocardial perfusion studies in diabetes mellitus. In 

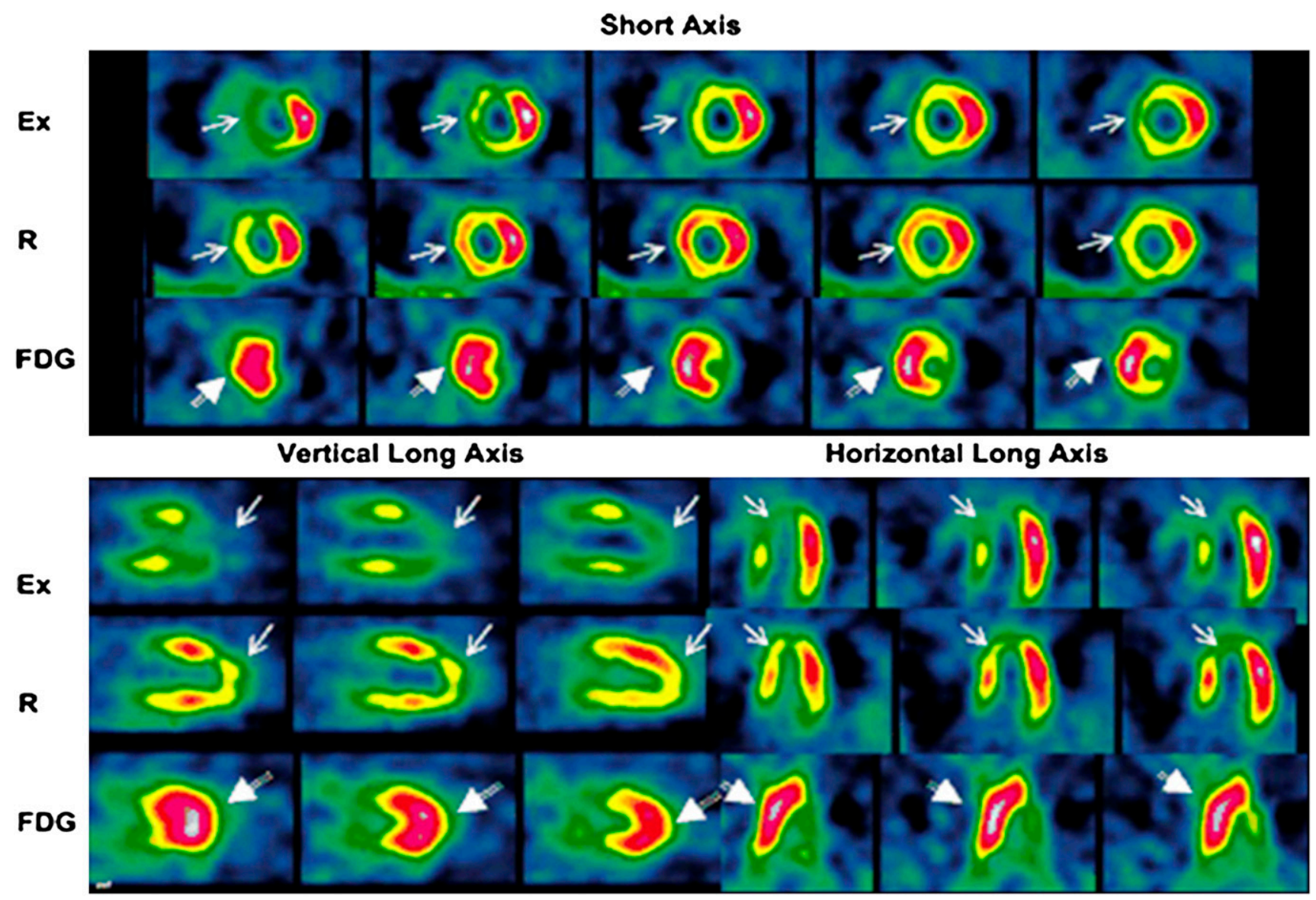

FIGURE 5. Simultaneous myocardial perfusion and metabolism imaging after dual intravenous injection of 99mTc-sestamibi and ${ }^{18} \mathrm{~F}-\mathrm{FDG}$ at peak exercise. Dual-isotope simultaneous acquisition was performed 40-60 min after exercise study was completed. Rest ${ }^{99 m}$ Tc-sestamibi imaging was performed separately. In this patient with angina and no prior myocardial infarction, there is evidence of extensive reversible perfusion defect in anterior, septal, and apical regions (arrows). Coronary angiogram showed $90 \%$ stenosis of left anterior descending and $60 \%$ of left circumflex coronary arteries. The corresponding ${ }^{18} \mathrm{~F}-\mathrm{FDG}$ image shows intense uptake in regions with reversible sestamibi defects (arrows), reflecting the metabolic correlate of exercise-induced myocardial ischemia. Ex = exercise; $\mathrm{R}$ = rest. (Adapted from (45).)

the meantime, the American Diabetes Association recommendations for cardiac testing among asymptomatic diabetics include the findings of an abnormal baseline ECG or new ischemic changes, concurrent cerebral or peripheral vascular disease, beginning a vigorous exercise program, and those with 2 risk factors for CAD (49).

ESRD. Cardiovascular disease accounts for most of the morbidity and mortality both in the predialysis stages of chronic kidney disease and after the onset of ESRD. It has been reported that those who have ESRD, and receive some form of dialysis, have as much as a 100-fold higher risk of death from cardiovascular disease than healthy people matched for age, race, and sex (50). In a prospective study of 130 asymptomatic ESRD patients undergoing hemodialysis, significant coronary artery luminal narrowing ( $\geq 75 \%$ ) was present in $71 \%$ of ESRD patients (51). The same investigators subsequently examined the prognostic significance of reduced myocardial metabolism with ${ }^{123}$ I-BMIPP in conjunction with perfusion abnormalities assessed with thallium in ESRD patients without prior myocardial infarction (52). Among the 318 asymptomatic hemodialysis patients who were prospectively enrolled in the study, $50(16 \%)$ died of cardiac events during a mean follow-up period of $3.6 \pm 1.0 \mathrm{y}$. There was significant association between abnormal ${ }^{123}$ I-BMIPP uptake (indicating myocardial ischemia) and subsequent cardiac death. Stepwise Cox hazard analysis showed that cardiac death was significantly associated with highly abnormal ${ }^{123} \mathrm{I}-$ BMIPP uptake (summed score of $\geq 12$; hazard ratio = $21.9)$ and age $(\geq 70 \mathrm{y}$; hazard ratio $=2.4)$. Among patients with a summed ${ }^{123}$ I-BMIPP score of $\geq 12$ event-free survival at $3 \mathrm{y}$ was $61 \%$, whereas for those with a summed ${ }^{123} \mathrm{I}-$ BMIPP score of $<12$ event-free survival was $98 \%$. When ${ }^{123}$ I-BMIPP uptake (metabolism) was assessed in relation to regional thallium uptake (perfusion), indicating myocardial ischemia, the sensitivity and specificity of metabolism:perfusion mismatch for predicting cardiac death were $86 \%$ and $88 \%$, respectively (52). These findings support the assertion that altered cardiac metabolism (indicating silent myocardial ischemia) is highly prevalent in ESRD patients and can identify the subgroup of patients who are at high-risk for cardiac death (53). 


\section{Absolute Blood Flow-Based Screening for Endothelial Dysfunction and Microvascular Disease}

Because current myocardial perfusion imaging techniques with SPECT assess regional myocardial blood flow distribution in terms of relative uptake, multivessel CAD resulting in equally restricted flow in all coronary distributions could be interpreted as a normal study. Similarly, the myocardial region with the highest radiotracer uptake (usually assigned as the reference region) is presumed to be supplied by a normal coronary artery. Such arteries may in fact have less severe flow-limiting disease or disease that is not yet flow-limiting.

Flow through the coronary arterial system is highly regulated by vasoconstrictive and vasodilatory mechanisms. Endothelial cell production of vasodilators, such as nitric oxide and adenosine, counteracts adrenergically driven vasoconstriction to meet changes in intracoronary pressure and oxygen demand. Endothelial dysfunction causes impaired stress-induced coronary artery vasodilation, which leads to diminished myocardial blood flow reserve, long before hemodynamically significant coronary artery stenosis develops (54). Endothelial dysfunction is also responsible for coronary spasms, leading to ischemia and anginal symptoms. Indeed, endothelial dysfunction has been established as a prognostic marker for cardiovascular outcomes (55). Assessment of myocardial blood flow reserve with PET allows characterization of endothelial dysfunction and may serve as a future platform for early identification of asymptomatic CAD.

Because of near-complete first-pass myocardial extraction and limited backdiffusion of PET tracers, the time required to obtain maximal myocardial uptake is dependent on the coronary flow velocity, thus making quantification of coronary blood flow achievable. Normal values for resting coronary flow have been established in resting conditions as well as in relation to cardiac work, described by the rate-pressure product $(56,57)$. Additionally, whereas coronary blood flow rates increase with age, the magnitude of increased flow from dipyridamole-stimulated hyperemia is not age-dependent (56). Reduced resting coronary flow and impaired increase in flow as a response to pharmacologic or cold pressor "stress" serve as markers of endothelial dysfunction. Impaired myocardial blood flow or flow reserve has been demonstrated in asymptomatic patients with elevated cholesterol (58), smoking (59), hypertension (60), and insulin resistance (61). In patients with single-vessel CAD undergoing flow-pressure measurements, flow resistance and fractional flow reserve were shown to be abnormal in $>50 \%$ of presumably normal vessels (62). Although there is unequivocal evidence that endothelial dysfunction is a relevant prognostic marker of future cardiac events $(47,63)$, only a few studies have shown that endothelial dysfunction is a relevant therapeutic target $(63,64)$. However, quantitative PET flow measurements have been used to demonstrate improvement in endothelial dysfunction and myocardial ischemia in patients with advanced CAD after medical treatment. An example of a patient exhibiting improvement in adenosine-stimulated hyperemia after $1 \mathrm{y}$ of treatment with 3-hydroxy-3-methylglutaryl coenzyme A reductase inhibitor is shown in Figure 6 (65). Further studies are needed to elucidate the role of PET-based coronary flow quantification in improving screening for preclinical CAD and the potential to guide therapeutic decisions.

\section{MOLECULAR IMAGING}

In the current era, diagnosis and treatment of cardiovascular disease is increasingly being defined by underlying
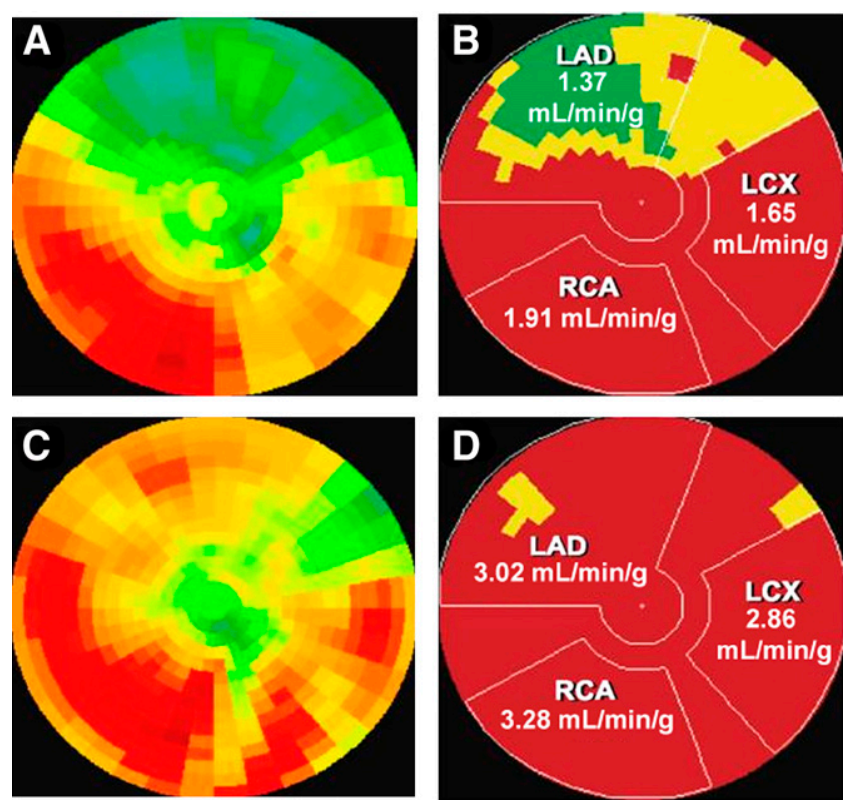

FIGURE 6. Polar map of myocardial tracer uptake during adenosine vasodilation is shown in a patient with CAD. (A) Relative distribution of the radiotracer (as would be the case with SPECT studies) suggests single-vessel disease in the territory of left anterior descending (LAD) artery. (B) Quantitative assessment of regional myocardial blood flow reserve with ${ }^{13} \mathrm{~N}-$ ammonia PET. In a vascular territory without significant coronary artery stenosis, a normal myocardial blood flow reserve is approximately $3 \mathrm{~mL} / \mathrm{min} / \mathrm{g}$. As such, quantitative myocardial blood flow assessment identifies abnormal flow reserve in all 3 vascular territories in this patient; $1.37 \mathrm{~mL} / \mathrm{min} / \mathrm{g}$ in $\mathrm{LAD}$ territory, $1.65 \mathrm{~mL} / \mathrm{min} / \mathrm{g}$ in left circumflex (LCX) territory, and $1.91 \mathrm{~mL} / \mathrm{min} / \mathrm{g}$ in right coronary artery (RCA) territory. The clinical implication for the presumed diagnosis of 1-vessel disease on evaluation of relative myocardial radiotracer uptake versus 3-vessel CAD on quantitative assessment of myocardial blood flow reserve is important and not inconsequential. Moreover, follow-up polar maps (C and D) acquired 1-y after medical therapy with pravastatin show significant improvement in myocardial flow reserve in all 3 vascular territories when compared with baseline values (A and $B$ ). The extent of the stress-induced defect decreased from $51 \%$ of LAD vascular territory to only $3 \%$. Moreover, there is increase and normalization in myocardial blood flow reserve in LCX and RCA vascular territories, which could be detected only on quantitative measurements of myocardial blood flow (D) but not on evaluation of the relative radiotracer uptake (C). (Adapted from (65).) 
molecular and genomic aberrations rather than by clinical signs and symptoms alone. Molecular imaging exploits the targeting of expressed cell-surface molecules, intracellular processes, and gene expression. Such information can potentially allow better disease definition, more effective choice of therapeutic intervention, and individualized monitoring of response to treatment.

\section{Prevention with Medical Therapy and Risk Factor Modification}

Aspirin and statins are useful in primary and secondary prevention of atherosclerosis and its associated comorbidities because of their antiplatelet, lipid-lowering, and antiinflammatory effects. As the natural history of atherosclerosis and the role of inflammation become increasingly understood, new pharmaceutical agents are likely to be developed. Nuclear molecular imaging of cellular and molecular events in the development of atherosclerosis will not only assist in furthering this understanding but will also help direct clinical management in the future.

Clinical efforts for risk factor modification, such as encouragement of smoking cessation and optimization of lipid and hypertension control, do not need risk stratification by stress testing but should be globally applied. Although localized therapies such as coronary stenting might stabilize rupture-prone lesions, current cardiac stress testing cannot direct such treatment options. As the goal of cardiac stress testing is to identify CAD so that management can be adjusted to prevent significant cardiovascular events, future cardiac stress testing should focus on characterization of the vulnerable plaque.

\section{Molecular Targets for Imaging Unstable Atherosclerotic Plaques}

Molecular imaging offers exciting opportunities to translate the continuously improving comprehension of the pathophysiology of atherosclerosis at the molecular and cellular levels to identification of the vulnerable plaque within the clinical realm. Atherosclerotic lesions slowly develop in the tunica intima with buildup of cellular and extracellular components originating from both the vessel lumen and the tunica media. Initial accumulation of fatladen macrophages (foam cells), T-lymphocytes, and smooth muscle cells is known as an intimal xanthoma or fatty streak. These preatherosclerotic lesions form shortly after birth and throughout life and commonly regress as their distribution changes from childhood to adult life beyond the third decade (66). A second preatherosclerotic lesion, known as intimal thickening, is comprised primarily of smooth muscle cells within a proteoglycan-rich matrix. Both of these preatherosclerotic lesions have the potential to develop into progressive atherosclerotic lesions (67). Progression of atherosclerotic lesions continues with the development of intimal xanthoma into a lipid-rich core that becomes covered with a fibrous cap comprised of smooth muscle cells and proteoglycan extracellular matrix. Cellular and molecular components associated with plaque progres- sion and instability include monocyte recruitment proteins, foam cells, matrix metalloproteinases, and apoptosis (68). There is potential for imaging unstable atherosclerotic plaques by targeting these components with molecular markers that are conjugated to a PET radiotracer. For example, ${ }^{125}$ I-labeled low-density lipoprotein has been used to image atherosclerotic disease in carotid arteries (69). A radionuclide target for macrophages, ${ }^{131} \mathrm{I}$-labeled monocyte chemoattractant protein-1, has been shown to accumulate in lipid-rich, macrophage-rich regions in animal models of atherosclerosis $(70,71)$. ${ }^{99 m}$ Tc-Labeled annexin V, which localizes to apopotic cells, may be useful in identifying unstable atherosclerotic plaques $(68,72)$. Finally, ${ }^{18} \mathrm{~F}-\mathrm{FDG}$ has increased uptake in inflamed vascular tissue and can serve as a marker for atherosclerosis (73). Rudd et al. have recently demonstrated that ${ }^{18} \mathrm{~F}$-FDG PET with coincident CT studies detects significant carotid artery plaques in patients with recent transient ischemic attack (74). Whether these favorable results in animals and humans can be translated into useful modalities for screening of preclinical unstable atherosclerosis remains untested.

\section{Molecular Targets for Imaging Myocardium}

Targeting intracellular metabolic processes of the myocardium or expressed cell-surface molecules for imaging should expand our ability to diagnose and treat subclinical LV dysfunction or progressive LV remodeling in patients with heart failure that often remain elusive with traditional imaging techniques. The fibrosis, apoptosis, and other cellular and molecular events involved in LV remodeling of heart failure might be assessed to improve understanding of the significance of these events in heart failure progression but also to track response to therapy. Similarly, cardiac transplant recipients undergo myocardial biopsy at best annually for monitoring of graft rejection. Identification of molecular markers associated with rejection that can be recognized by nuclear probes should replace the necessity for this routine invasive testing. Success in cardiac arrhythmia ablations is increasing with improved use of imaging techniques (Fig. 7). Identification of molecular or cellular markers associated with arrhythmias may enhance imaging techniques and further improve the efficacy of ablations or provide new therapeutic options for ablation. Another important area in cardiology is the potential for cardiac regeneration in postmyocardial infarction and heart failure patients. Nuclear imaging of steps in regeneration should help advance this field and assist its realization as a new frontier in cardiac medicine.

Targeting Myocardial Metabolism. Metabolic adaptation likely represents one of the earliest responses to myocardial ischemia, which is regulated to protect the structural and functional integrity of the heart. Ischemia may be transitory and reversible, or permanent and irreversible, leading to myocardial infarction. Myocardial ischemia may also lead to postischemic stunning, hibernation, and preconditioning. A decrease in oxygen delivery to the myocardium results in 

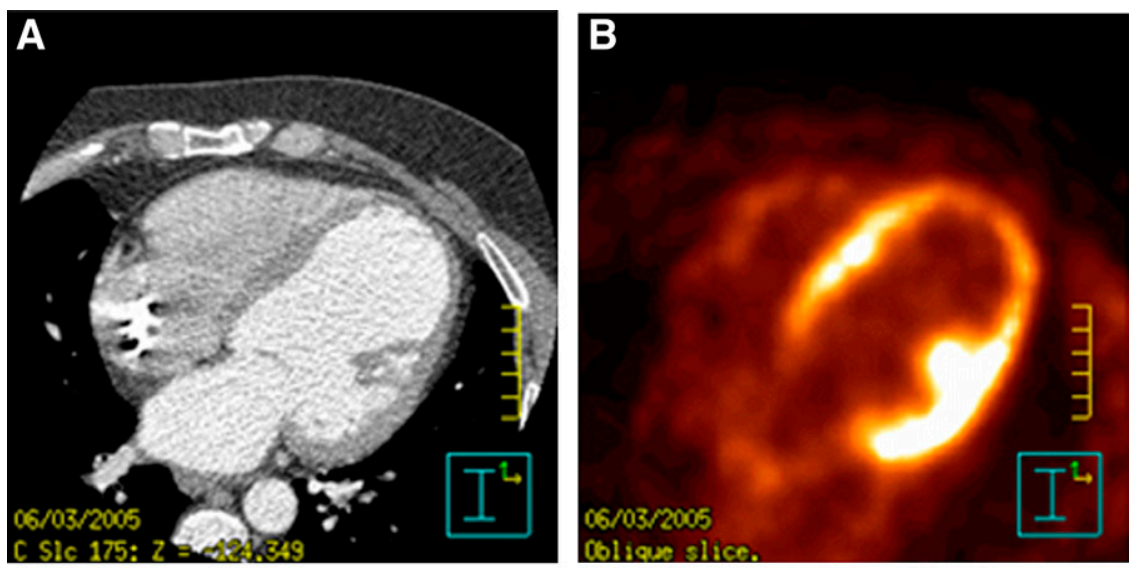

FIGURE 7. Transverse CT, PET, and integrated PET/CT images of the heart from a patient with ischemic cardiomyopathy are shown. (A) CT image shows abnormal thinning of the apical and apicolateral regions of the LV and preserved wall thickness in the septal and lateral regions. (B) Corresponding ${ }^{18} \mathrm{~F}$ FDG PET image shows preserved metabolic activity in septal and lateral regions and relatively decreased metabolic activity in apical and apicolateral regions. (C) Integrated PET/CT image (C) provides accurate coregistration of the limitedspatial-resolution metabolic signal of PET with the high-resolution anatomic signal of CT. (Adapted from (30).)

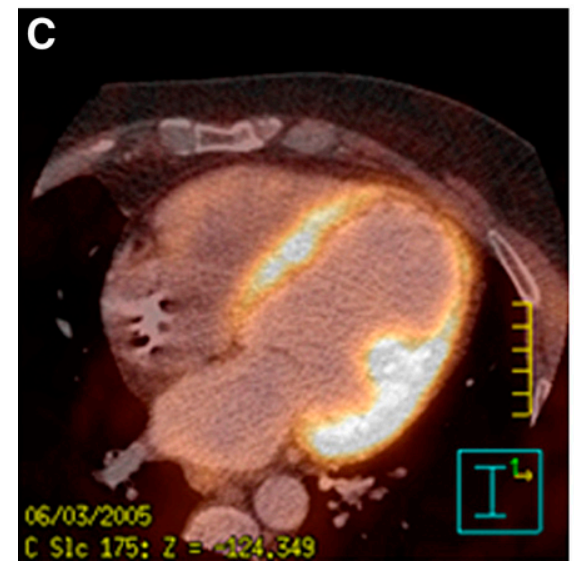

the downregulation of mitochondrial oxidative metabolism and reduced contractile function. The heart helps protect itself from the oxygen-lack fate of infarction by switching its energy source from aerobic to anaerobic glycolysis. While such a metabolic switch has been well established in chronically hypoperfused myocardium, termed hibernation, the metabolic consequences of hypoxia in the setting of acute or transient ischemia is less well established (75). Acute switch from aerobic to anaerobic metabolism may be a crucial condition for immediate cell survival after acute or transient myocardial ischemia. Without these refined adaptive changes in metabolism, the resultant energy deficit could lead to cell death, either by apoptosis or necrosis. Thus, targeting intracellular metabolic processes for imaging will undoubtedly expand our ability to diagnose and treat subclinical or progressive cardiovascular disorders $(45,52,53)$.

Targeting Cardiac Sympathetic Innervation. Imaging of cardiac sympathetic innervation with ${ }^{123}$ I-metaiodobenzylguanidine ( $\left.{ }^{123} \mathrm{I}-\mathrm{MIBG}\right)$ is an emerging area of risk stratification. MIBG is an analog of guanethidine and acts as a false adrenergic neurotransmitter. Mismatches between myocardial innervation and perfusion are common in patients with ischemic heart disease. Regional denervation of the heart in the postischemic myocardium may persist for $15 \mathrm{~d}$ or longer after an ischemic event. In the postmyocardial infarction setting, the territory of abnormal
${ }^{123}$ I-MIBG uptake (corresponding to sympathetic denervation) often exceeds the final infarct size, and such patients are at higher risk for subsequent ventricular arrhythmias (76-78). Similarly, in patients with LV dysfunction and heart failure, decreased ${ }^{123}$ I-MIBG uptake in the heart is associated with poor clinical outcome (79). Should these findings prove prognostic for outcomes in a larger number of patients with LV dysfunction, ${ }^{123}$ I-MIBG imaging may have a role in selecting patients who may optimally benefit from defibrillators (76). ${ }^{123}$ I-MIBG has been available in Europe for $>10 \mathrm{y}$, but it is not FDA approved for cardiac application in the United States.

Targeting Tissue Angiotensin-Converting Enzyme (ACE). The renin-angiotensin system and its primary effector peptide, angiotensin II, have been implicated in the pathophysiology of interstitial fibrosis, LV remodeling, and heart failure. The discovery of the tissue ACE system and its ability for local production of angiotensin II in the heart (beyond the circulatory system) provides the potential of ACE imaging in the heart and monitoring LV remodeling (80). Experiments using ${ }^{125}$ I-labeled angiotensin I and angiotensin II infusions have shown that $>90 \%$ of cardiac tissue angiotensin I and $>75 \%$ of cardiac tissue angiotensin II are synthesized in situ and are not derived from circulation (81). It is believed that the knowledge of tissue expression of the renin-angiotensin system may have important implications in management of heart failure patients (82). 
Consequently, a new radiolabeled ACE inhibitor, ${ }^{18} \mathrm{~F}-$ fluorobenzoyl-lisinopril, was recently synthesized without compromising its affinity for tissue ACE (83). In explanted cardiac tissues from patients with chronic ischemic heart disease, a specific binding of ${ }^{18} \mathrm{~F}$-fluorobenzoyl-lisinopril to ACE was shown, which was about twice as great as the nonspecific binding (80). Furthermore, the binding of ${ }^{18} \mathrm{~F}$ fluorobenzoyl-lisinopril was nonuniform in infarct, periinfarct, and remote, noninfarct myocardial segments. These preliminary data in ex vivo human tissues set the stage for future probes that target LV remodeling with radionuclide techniques. This should allow a more judicious use of neurohumoral antagonists especially in the subjects who do not show a manifestation of heart failure (84). In others, specific targeted imaging may allow timely selection of individualized treatment strategies and ensure optimization of therapeutic intervention.

Radionuclide Imaging of Cell- or Gene-Based Regenerative Therapy. Targeted implantation of autologous skeletal myoblasts, bone marrow stromal cells, hematopoietic stem cells, or local gene delivery may functionally revitalize scarred, noncontractile myocardial regions. Cell-based therapy for the treatment of heart disease has become a clinical reality. Radionuclide imaging of the fate of myogenic cell grafts and therapeutic genes in vivo may provide insight into cell survival and proliferation and the mechanism by which they improve cardiac function or prevent remodeling. In animal studies, transplanted cardiomyoblasts expressing a PET reporter gene have been imaged longitudinally with micro-PET to gain insight into the pattern of cell survival (85). Future applications of PET and SPECT in human studies include characterization, visual representation, and quantification of cell survival and response to gene-based regenerative therapies.

\section{CONCLUSION}

The new healthcare trend in cardiovascular diseases suggests a paradigm shift from detection and treatment of $\mathrm{CAD}$ to prediction and prevention of CAD. Although efforts to improve on limitations and exploit strengths of current myocardial perfusion methods will continue, it is likely that greater accessibility to CT angiography will fuel the growth in myocardial perfusion imaging, with the need to carefully assess the physiologic significance of imaged anatomic lesions and high calcium score, preferably in absolute quantitative terms. A further understanding of CAD pathophysiology at the molecular and cellular levels will allow radionuclide imaging to evolve into a primary prevention tool by earlier detection of atherosclerosis as well as identification of vulnerable plaques and adaptations in myocardial metabolism.

Radionuclide tracers by their nature reflect physiologic processes at the cellular level. Nuclear imaging techniques are well suited for cardiac molecular imaging because of their relatively high intrinsic sensitivity and excellent depth penetration. Hence, in the era of molecular medicine, nuclear cardiology is uniquely primed to provide insight into underlying molecular and genomic aberrations of cardiovascular disease and foster the development of innovative therapeutic interventions in the future.

\section{REFERENCES}

1. Thom T, Haase N, Rosamond W, et al. Heart disease and stroke statistics: 2006 update-A report from the American Heart Association Statistics Committee and Stroke Statistics Subcommittee. Circulation. 2006;113:e85-e151.

2. Gaziano JM. Global burden of cardiovascular disease. IN: Libby P, Braunwald E, eds, Braunwald's Heart Disease. 8th ed. Philadelphia, PA: Saunders-Elsevier Publishing Co., Inc., 2008:1-22.

3. Lloyd-Jones DM, Larson MG, Beiser A, Levy D. Lifetime risk of developing coronary heart disease. Lancet. 1999;353:89-92.

4. Gould KL, Lipscomb K. Effects of coronary stenoses on coronary flow reserve and resistance. Am J Cardiol. 1974;34:48-55.

5. Feil H, Siegel M. Electrocardiographic changes during attacks of angina pectoris. Am J Med Sci. 1928;175:255-260.

6. Master A, Oppenheimer E. A simple exercise tolerance test for circulatory efficiency with standard tables for normal individuals. Am J Med Sci. 1929; 177:223-243.

7. Master A, Jaffe H. The electrocardiographic changes after exercise in angina pectoris. J Mt Sinai Hosp. 1941;7:629-636.

8. Gianrossi R, Detrano R, Mulvihill D, et al. Exercise-induced ST depression in the diagnosis of coronary artery disease: a meta-analysis. Circulation. 1989;80: 87-98.

9. Gibbons RJ, Balady GJ, Bricker JT, et al. ACC/AHA 2002 Guideline Update for Exercise Testing: A Report of the American College of Cardiology/American Heart Association Task Force on Practice Guidelines (Committee on Exercise Testing). Boston, MA: American College of Cardiology Foundation and American Heart Association, Inc.; 2002. J Am Coll Cardiol. 2002;40:1531-1540.

10. Kaplan MA, Harris CN, Aronow WS, Parker DP, Ellestad MH. Inability of the submaximal treadmill stress test to predict the location of coronary disease. Circulation. 1973;47:250-256.

11. Mark DB, Hlatky MA, Harrell FE Jr, Lee KL, Califf RM, Pryor DB. Exercise treadmill score for predicting prognosis in coronary artery disease. Ann Intern Med. 1987;106:793-800

12. Chaitman BR. Exercise stress testing. In: Braunwald E, ed. Heart Disease: A Textbook of Cardiovascular Medicine. Vol 1. Philadelphia, PA: W. B. Saunders Co.; 1997:153-176.

13. Mark DB, Shaw L, Harrell FE Jr, et al. Prognostic value of a treadmill exercise score in outpatients with suspected coronary artery disease. $N$ Engl J Med. 1991;325:849-853.

14. Zaret BL, Strauss HW, Martin ND, Wells HP Jr, Flamm MD Jr. Noninvasive regional myocardial perfusion with radioactive potassium: study of patients at rest, with exercise and during angina pectoris. N Engl J Med. 1973;288:809-812.

15. Strauss HW, Harrison K, Langan JK, Lebowitz E, Pitt B. Thallium-201 for myocardial imaging: relation of thallium-201 to regional myocardial perfusion. Circulation. 1975;51:641-645.

16. Gibbons RJ, Balady GJ, Bricker JT, et al. ACC/AHA 2002 guideline update for exercise testing: summary article-A report of the American College of Cardiology/American Heart Association Task Force on Practice Guidelines (Committee to Update the 1997 Exercise Testing Guidelines). J Am Coll Cardiol. 2002;40:1531-1540.

17. Frans J, Wackers FJ. SPECT detection of coronary artery disease. In: Dilsizian V, Narula J, eds. Atlas of Nuclear Cardiology. Philadelphia, PA: Current Medicine, Inc.; 2003:63-77.

18. Stewart RE, Schwaiger M, Molina E, et al. Comparison of rubidium-82 positron emission tomography and thallium-201 SPECT imaging for detection of coronary artery disease. Am J Cardiol. 1991;67:1303-1310.

19. Carrea JR, Gleason G, Shaw J, Krontz B. The direct diagnosis of myocardial infarction by photoscanning after administration of cesium-131. Am Heart J. 1964;68:627-636.

20. Schelbert HR, Wisenberg G, Phelps ME, et al. Noninvasive assessment of coronary stenoses by myocardial imaging during pharmacologic coronary vasodilation. VI. Detection of coronary artery disease in human beings with intravenous N-13 ammonia and positron computed tomography. Am J Cardiol. 1982;49:1197-1207.

21. Gould KL, Goldstein RA, Mullani NA, et al. Noninvasive assessment of coronary stenoses by myocardial perfusion imaging during pharmacologic 
coronary vasodilation. VIII. Clinical feasibility of positron cardiac imaging without a cyclotron using generator-produced rubidium-82. J Am Coll Cardiol. 1986;7:775-789.

22. Pohost GM, Zir LM, Moore RH, McKusick KA, Guiney TE, Beller GA. Differentiation of transiently ischemic from infarcted myocardium by serial imaging after a single dose of thallium-201. Circulation. 1977;55:294-302.

23. Kiat H, Berman DS, Maddahi J, et al. Late reversibility of tomographic myocardial thallium-201 defects: an accurate marker of myocardial viability. J Am Coll Cardiol. 1988;12:1456-1463.

24. Ragosta M, Beller GA, Watson DD, Kaul S, Gimple LW. Quantitative planar rest-redistribution ${ }^{201} \mathrm{Tl}$ imaging in detection of myocardial viability and prediction of improvement in left ventricular function after coronary bypass surgery in patients with severely depressed left ventricular function. Circulation. 1993;87:1630-1641

25. Dilsizian V, Rocco TP, Freedman NM, Leon MB, Bonow RO. Enhanced detection of ischemic but viable myocardium by the reinjection of thallium after stress-redistribution imaging. N Engl J Med. 1990;323:141-146.

26. Kitsiou AN, Srinivasan G, Quyyumi AA, Summers RM, Bacharach SL, Dilsizian V. Stress-induced reversible and mild-to-moderate irreversible thallium defects: Are they equally accurate for predicting recovery of regional left ventricular function after revascularization? Circulation. 1998;98:501-508.

27. Udelson JE, Coleman PS, Metherall J, et al. Predicting recovery of severe regional ventricular dysfunction: comparison of resting scintigraphy with ${ }^{201} \mathrm{Tl}$ and ${ }^{99 \mathrm{~m}}$ Tc-sestamibi. Circulation. 1994;89:2552-2561.

28. Lodge MA, Braess H, Mahmoud F, et al. Developments in nuclear cardiology: transition from single photon emission computed tomography to positron emission tomography-computed tomography. J Invasive Cardiol. 2005;17:491-496.

29. Nieman K. MDCT coronary imaging. In: Dilsizian V, Pohost GM, eds. Cardiac CT, PET, and MR. 1st ed. Malden MA, ed. Blackwell Publishing Co., Inc; 2006:192-204.

30. Braess H, Dilsizian V. PET and CT in cardiac imaging: Is a paradigm shift from SPECT to hybrid PET/CT inevitable? In: Dilsizian V, Pohost GM, eds. Cardiac CT, PET and MR. 1st ed. Malden MA, ed. Blackwell Publishing Co., Inc.; 2006:238-255.

31. Patton JA, Slomka PJ, Germano G, Berman DS. Recent technologic advances in nuclear cardiology. J Nucl Cardiol. 2007;14:501-513.

32. Berman DS, Hachamovitch R, Shaw LJ, et al. Roles of nuclear cardiology, cardiac computed tomography, and cardiac magnetic resonance: noninvasive risk stratification and a conceptual framework for the selection of noninvasive imaging tests in patients with known or suspected coronary artery disease. $\mathrm{J} \mathrm{Nucl}$ Med. 2006;47:1107-1118.

33. Yoshinaga K, Chow BJ, Williams K, et al. What is the prognostic value of myocardial perfusion imaging using rubidium-82 positron emission tomography? J Am Coll Cardiol. 2006;48:1029-1039.

34. Schor S, Behar S, Modan B, Barell V, Drory J, Kariv I. Disposition of presumed coronary patients from an emergency room: a follow-up study. JAMA. 1976;236: 941-943.

35. Lee TH, Ting HH, Shammash JB, Soukup JR, Goldman G. Long-term survival of emergency department patients with acute chest pain. Am J. Cardiol. 1992;69: $145-151$.

36. Lee TH, Rouan GW, Weisberg MC, et al. Clinical characteristics and natural history of patients with acute myocardial infarction sent home from the emergency room. Am J Cardiol. 1987;60:219-224.

37. McCarthy BD, Beshansky JR, D'Agostino RB, et al. Missed diagnoses of acute myocardial infarction in the emergency department: results from a multicenter study. Ann Emerg Med. 1993;22:579-582.

38. Klocke FJ, Baird MG, Lorell BH, et al. ACC/AHA/ASNC guidelines for the clinical use of cardiac radionuclide imaging: executive summary-A report of the American College of Cardiology/American Heart Association Task Force on Practice Guidelines (ACC/AHA/ASNC Committee to Revise the 1995 Guidelines for the Clinical Use of Cardiac Radionuclide Imaging). Circulation. 2003;108:1404-1418.

39. Udelson JE, Beshansky JR, Ballin DS, et al. Myocardial perfusion imaging for evaluation and triage of patients with suspected acute cardiac ischemia: a randomized controlled trial. JAMA. 2002;288:2693-2700.

40. Hoffmann U, Nagurney JT, Moselewski F, et al. Coronary multidetector computed tomography in the assessment of patients with acute chest pain. Circulation. 2006;114:2251-2260.

41. White CS, Kuo D, Kelemen M, et al. Chest pain evaluation in the emergency department: Can MDCT provide a comprehensive evaluation? AJR. 2005;185: 533-540.

42. Goldstein JA, Gallagher MJ, O'Neill WW, Ross MA, O'Neil BJ, Raff GL. A randomized controlled trial of multi-slice coronary computed tomography for evaluation of acute chest pain. J Am Coll Cardiol. 2007;49:863-871.
43. Kawai Y, Tsukamoto E, Nozaki Y, Morita K, Sakurai M, Tamaki N. Significance of reduced uptake of iodinated fatty acid analogue for the evaluation of patients with acute chest pain. J Am Coll Cardiol. 2001;38:1888-1894.

44. Dilsizian V, Bateman TM, Bergmann SR, et al. Metabolic imaging with betamethyl-p-[ $\left.{ }^{123} \mathrm{I}\right]$-iodophenyl-pentadecanoic acid identifies ischemic memory after demand ischemia. Circulation. 2005;112:2169-2174.

45. He ZX, Shi RF, Wu YJ, et al. Direct imaging of exercise-induced myocardial ischemia with fluorine-18-labeled deoxyglucose and Tc-99m-sestamibi in coronary artery disease. Circulation. 2003;108:1208-1213.

46. De Lorenzo A, Lima RS, Siqueira-Filho AG, Pantoja MR. Prevalence and prognostic value of perfusion defects detected by stress technetium- $99 \mathrm{~m}$ sestamibi myocardial perfusion single-photon emission computed tomography in asymptomatic patients with diabetes mellitus and no known coronary artery disease. Am J Cardiol. 2002;90:827-832.

47. Scholte AJ, Bax JJ, Wackers FJ. Screening of asymptomatic patients with type 2 diabetes mellitus for silent coronary artery disease: combined use of stress myocardial perfusion imaging and coronary calcium scoring. J Nucl Cardiol. 2006;13:11-18.

48. Wackers FJ, Young LH, Inzucchi SE, et al. Detection of silent myocardial ischemia in asymptomatic diabetic subjects: the DIAD study. Diabetes Care. 2004;27:1954-1961.

49. Consensus development conference on the diagnosis of coronary heart disease in people with diabetes: 10-11 February, 1998, Miami, Florida; American Diabetes Association. Diabetes Care. 1998;21:1551-1559.

50. Levey AS, Beto JA, Coronado BE, et al. Controlling the epidemic of cardiovascular disease in chronic renal disease: What do we know? What do we need to learn? Where do we go from here? Am J Kidney Dis. 1998;32:853908.

51. Nishimura M, Hashimoto T, Kobayashi H, et al. Myocardial scintigraphy using a fatty acid analogue detects coronary artery disease in hemodialysis patients. Kidney Int. 2004;66:811-819.

52. Nishimura M, Tsukamoto K, Hasebe N, Tamaki N, Kikuchi K, Ono, T. Prediction of cardiac death in hemodialysis patients by myocardial fatty acid imaging. Am Coll Cardiol. 2008;51:139-145.

53. Dilsizian V, Fink J. Deleterious Effect of Altered Myocardial Fatty Acid Metabolism in Kidney Disease. J Am Coll Cardiol. 2008;51:146-148.

54. Camici PG, Crea F. Coronary microvascular dysfunction. N Engl J Med. 2007; 22:830-840

55. Schachinger V, Britten MB, Zeiher AM. Prognostic impact of coronary vasodilator dysfunction on adverse long-term outcome of coronary heart disease. Circulation. 2000;101:1899-1906.

56. Czernin J, Muller P, Chan S, et al. Influence of age and hemodynamics on myocardial blood flow and flow reserve. Circulation. 1993;88:62-69.

57. Chareonthaitawee P, Kaufmann PA, Rimoldi O, Camici PG. Heterogeneity of resting and hyperemic myocardial blood flow in healthy humans. Cardiovasc Res. 2001;50:151-161.

58. Guethlin M, Kasel AM, Coppenrath K, Ziegler S, Delius W, Schwaiger M. Delayed response of myocardial flow reserve to lipid-lowering therapy with fluvastatin. Circulation. 1999;99:475-481.

59. Czernin J, Sun K, Brunken R, Bottcher M, Phelps M, Schelbert H. Effect of acute and long-term smoking on myocardial blood flow and flow reserve. Circulation. 1995;91:2891-2897.

60. Masuda D, Nohara R, Tamaki N, et al. Evaluation of coronary blood flow reserve by ${ }^{13} \mathrm{~N}-\mathrm{NH} 3$ positron emission computed tomography (PET) with dipyridamole in the treatment of hypertension with the ACE inhibitor (Cilazapril). Ann Nucl Med. 2000;14:353-360.

61. Prior JO, Quinones MJ, Hernandez-Pampaloni M, et al. Coronary circulatory dysfunction in insulin resistance, impaired glucose tolerance, and type 2 diabetes mellitus. Circulation. 2005;111:2291-2298.

62. Di Carli M, Czernin J, Hoh CK, et al. Relation among stenosis severity, myocardial blood flow, and flow reserve in patients with coronary artery disease. Circulation. 1995;91:1944-1951.

63. Modena MG, Bonetti L, Coppi F, Bursi F, Rossi R. Prognostic role of reversible endothelial dysfunction in hypertensive postmenopausal women. J Am Coll Cardiol. 2002;40:505-510.

64. Cohn JN, Quyyumi AA, Hollenberg NK, Jamerson KA. Surrogate markers for cardiovascular disease: functional markers. Circulation. 2004;109(25 suppl 1): IV31-IV46.

65. Schindler TH, Schelbert HR. PET quantitation of myocardial blood flow. In: Dilsizian V, Narula J, eds. Atlas of Nuclear Cardiology. 2nd ed. Philadelphia, PA: Current Medicine, Inc.; 2006:67-96.

66. Velican C, Velican D. The precursors of coronary atherosclerotic plaques in subjects up to 40 years old. Atherosclerosis. 1980;37:33-46. 
67. Virmani R, Kolodgie FD, Burke AP, Farb A, Schwartz SM. Lessons from sudden coronary death: a comprehensive morphological classification scheme for atherosclerotic lesions. Arterioscler Thromb Vasc Biol. 2000;20:1262-1275.

68. Davies JR, Rudd JH, Weissberg PL, Narula J. Radionuclide imaging for the detection of inflammation in vulnerable plaques. J Am Coll Cardiol. 2006;47(8 suppl):C57-C68.

69. Lees RS, Lees AM, Strauss HW. External imaging of human atherosclerosis. J Nucl Med. 1983;24:154-156.

70. Narula J, Virmani R, Zaret BL. Radionuclide imaging of atherosclerotic lesions. In: Dilsizian V, Narula J, eds. Atlas of Nuclear Cardiology. Philadelphia, PA: Current Medicine, Inc.; 2003:217-236.

71. Ohtsuki K, Hayase M, Akashi K, Kopiwoda S, Strauss HW. Detection of monocyte chemoattractant protein-1 receptor expression in experimental atherosclerotic lesions: an autoradiographic study. Circulation. 2001;104:203-208.

72. Kietselaer BL, Reutelingsperger CP, Heidendal GA, et al. Noninvasive detection of plaque instability with use of radiolabeled annexin A5 in patients with carotidartery atherosclerosis. N Engl J Med. 2004;350:1472-1473.

73. Strauss WH, Mari C, Patt BE, Ghazarossian V. Intravascular radiation detectors for the detection of vulnerable atheroma. J Am Coll Cardiol. 2006;47:C97C100.

74. Rudd JH, Warburton EA, Fryer TD, et al. Imaging atherosclerotic plaque inflammation with $\left[{ }^{18} \mathrm{~F}\right]$-fluorodeoxyglucose positron emission tomography. Circulation. 2002;105:2708-2711.

75. Tillisch J, Brunken R, Marshall R, et al. Reversibility of cardiac wall-motion abnormalities predicted by positron tomography. N Engl J Med. 1986;314:884888 .
76. Arora R, Ferrick KJ, Nakata T, et al. I-123 MIBG imaging and heart rate variability analysis to predict the need for an implantable cardioverter defibrillator. J Nucl Cardiol. 2003;10:121-131.

77. Carrio I. Cardiac neurotransmission imaging. J Nucl Med. 2001;42:1062-1076.

78. Udelson JE, Shafer CD, Carrio I. Radionuclide imaging in heart failure: assessing etiology and outcomes and implications for management. $\mathrm{J} \mathrm{Nucl}$ Cardiol. 2002;9(5 suppl):40S-52S.

79. Merlet P, Valette H, Dubois-Rande JL, et al. Prognostic value of cardiac metaiodobenzylguanidine imaging in patients with heart failure. $\mathrm{J} \mathrm{Nucl} \mathrm{Med}$. 1992;33:471-477.

80. Dilsizian V, Eckelman WC, Loredo ML, Jagoda EM, Shirani J. Evidence for tissue angiotensin-converting enzyme in explanted hearts of ischemic cardiomyopathy using targeted radiotracer technique. J Nucl Med. 2007;48:182-187.

81. De Mello WC, Danser AH. Angiotensin II and the heart: on the intracrine reninangiotensin system. Hypertension. 2000;35:1183-1188.

82. Dzau VJ, Bernstein K, Celermajer D, et al. The relevance of tissue angiotensinconverting enzyme: manifestations in mechanistic and endpoint data. Am J Cardiol. 2001;88(9A):1L-20L.

83. Lee YHC, Kiesewetter DO, Lang L, et al. Synthesis of $4-\left[{ }^{18} \mathrm{~F}\right]$ fluorobenzoyllisinopril: a radioligand for angiotensin converting enzyme (ACE) imaging with positron emission tomography. J Labelled Compds Radiopharm. 2001;44:S268-S270.

84. Chandrashekhar Y, Narula J. Exposing ACE up the sleeve [editorial]. J Nucl Med. 2007;48:173-174.

85. Wu JC, Chen IY, Sundaresan G, et al. Molecular imaging of cardiac cell transplantation in living animals using optical bioluminescence and positron emission tomography. Circulation. 2003;108:1302-1305. 